\title{
Research on Education Quality of Chinese Kindergartens: Current Situation and Enlightenment
}

\author{
Wang Wei ${ }^{1} \&$ Li Jing ${ }^{1}$ \\ ${ }^{1}$ Faculty of Education, Southwest University, Chongqing, China \\ Correspondence: Wang Wei, Faculty of Education, Southwest University, No. 2 Tiansheng Road, Beibei, \\ Chongqing 400715, P. R. China. E-mail: wangwei200303@163.com
}

\author{
Received: July 3, 2014 Accepted: August 5, 2014 Online Published: August 15, 2014 \\ doi:10.5539/ass.v10n18p43 URL: http://dx.doi.org/10.5539/ass.v10n18p43
}

\begin{abstract}
The thesis mainly adopts content analysis method to analyze 466 literature samples from dimensions such as research results type distribution and time distribution, research topic and content, research method and so on. The research results show that the existing research literatures on education quality of kindergarten are mainly academic periodicals and journals, and the literature quantity has realized a sustainable growth since 2006 due to policy support, and the researches comprehensively cover the most topics related to kindergarten education quality such as the concept of quality, the elements of quality, quality current situation, relevant evaluation standard, evaluation tools, evaluation current state and quality assurance. However, there also exist some problems such as simplification of research method and shortage of empirical research. Therefore, Chinese scholars should conduct more empirical researches rooted in practice and based on real problems so as to enhance interactive effects between academic research and practice reform as well as the interactive effects between academic research and policy formulation.
\end{abstract}

Keywords: kindergarten education, education quality, research status

\section{Introduction}

A large number of studies have shown that early childhood education can bring broad benefits (Heckman et al., 2007, 2009; Nores \& Barnett, 2010; Sylva et al., 2004, 2006; Sheridan, 2007), for example, it can lay a good foundation for the happiness and lifelong learning of children, reduce poverty, facilitate educational fairness, promote intergenerational communication, cultivate human capital, and accelerate the development of society and economy (OECD, 2012). Larry Schweinhart (1993) and Reynolds A (2002) et al. who made tracking studies on early education programs of The High/Scope Perry Preschool and Chicago Child-parent Center Program, have found that the rate of return on investment of early education is about 1: 7.16. The recent analysis on cost and benefit of this research indicates that the total rate of return on investment of these children at age of 40 reaches as highly as 1:17.07, of which the children's personal rate of return is 1:4.17 and the social rate of return is 1: 12.9 (Schweinhart, 2005). Based on these, the researchers believe that early childhood education is helpful to promote developments of educational fairness and social harmony, and the investment on early childhood education should be regarded as accumulated wealth to the nation rather than a burden.

Although the researches have shown that early education quality can bring huge benefits, all of the benefits are based on the "good quality"; the poor quality preschool education services will do nothing good to the individual and society and even will hinder the development of individuals and the society (OECD, 2012). The global monitoring on education for all has also found that many countries committed to ensuring the education rights of all children have ignored education quality because of emphasizing on education opportunities (UNESCO, 2007). Opportunity and quality are equally important. Without the basic guarantee of quality, opportunity for children to enter kindergarten is almost meaningless for the development of young children (Feng, 2011). Nowadays, with the rapid popularization of early education and the increase of kindergarten enrolment rate in China, the education quality, however, is often ignored or placed at the second place. In recent years, some Chinese kindergartens have brought in some education content and forms that not conform to the characteristics of children's physical and mental development, have hired unqualified teachers, and even have unqualified basic education and teaching conditions, all of which have seriously affected children's physical and mental health (Liu, 2010). 
How to popularize qualified education is the key point for the present and future researches on pre-school education and policy-making in China, and it needs educational circles to conduct empirical researches and provide support for policy formulation. What is the current research situation of Chinese kindergarten education quality? What results have achieved? What should be further strengthened and improved? Whether it can provide effective intellectual support for the improvement of kindergarten education quality? Based on these questions, the thesis makes a review and analysis on the research status of kindergarten education quality.

\section{Research Methods}

\subsection{Sampling Method and Analysis Tool}

This research made an accurate retrieval for all literatures titled with "kindergarten education" and "quality", "preschool education" and "quality", "infant education" and "quality", "early childhood education" and "quality" that recorded from January $1^{\text {st }} 1949$ to December $31^{\text {st }} 2013$ in the database of China National Knowledge Infrastructure (CNKI) (Note 1) and the total number of such literatures was 466 (Note 2). This research mainly adopts tools such as Excel 2007 and SPSS17.0 to make data analysis and process.

\subsection{Analysis Framework}

This research mainly uses content analysis method to make meta-analysis on study samples and also makes data extraction of the 466 retrieved literatures from dimensions such as the research result type distribution and time distribution, research topic and content, research method and so on. On this basis, it conducts quantitative and qualitative analyses to the research status of kindergarten education quality in China.

\section{Research Results}

\subsection{Research Status and Trend Analysis}

In accordance with the types of retrieved literatures, it analyzes and roughly gets the type distribution of research results of kindergarten education quality (See Figure 1). As shown in Figure 1, we can see that: (1) more than two/thirds of main existing research results are stated in journal articles while almost a quarter of results are presented in newspapers, which indicates that the research results are of timeliness. (2) The proportion of results stated in academic dissertation is very small, which reflects that "kindergarten education quality" has not drawn extensive attention of graduate students.

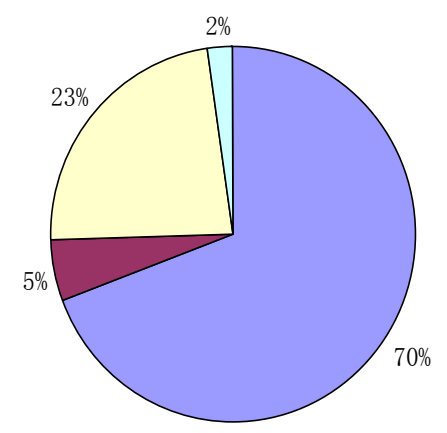

Figure 1. Type distribution of research results of kindergarten education quality

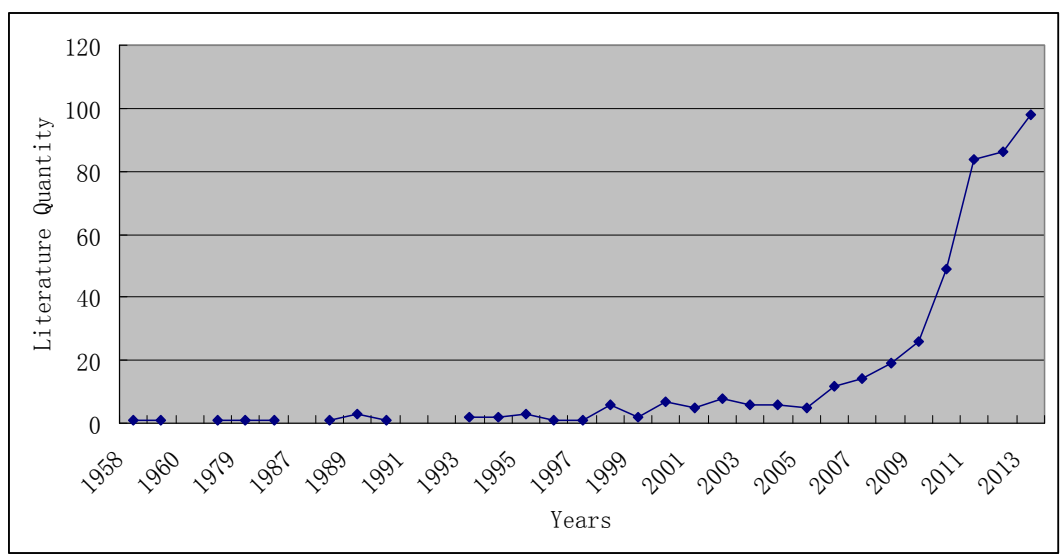

Figure 2. Time distribution of research results of kindergarten education quality 
Based on the longitudinal time sequence and through the quantitative analysis of the retrieved literatures, it generally gets the research development course of kindergarten education quality in the mainland of China (See Figure 2). The existing literatures show that earliest researches on early childhood education quality started from 1985, and the research gets its first remarkable node in 2006 and then the number of related literatures begins to rise. The second remarkable node for researches on early childhood education is in the year of 2010 after which the number of related literatures begins to enjoy a rapid rise. It is aroused by relevant policy document; since 2010, the Chinese government has begun to issue documents to support the development of preschool education.

Generally speaking, the researches related to "kindergarten education quality" in recent years mainly conduct qualitative and quantitative researches on public kindergartens from dimensions of the connotation of kindergarten education quality (Liu, 2012; Su \& Xu, 2010), the evaluation and promotion of Chinese kindergarten education quality (Liu Zhanlan, 2012), the quality evaluation standard and current situation (Liu, 2008; Liu, 2011; Wu, 2012), the quality evaluation index system (Xue, 2012) and etc.

\subsection{Main Research Topic and Evaluations}

\subsubsection{Discussions about the Quality Concept of Kindergarten Education}

Chinese scholars have discussed the quality concept, "being centered from the development of children", from different angles. Main points are: the high quality early childhood education should be based on the lifelong sustainable development of children and its goal should be to cultivate well-rounded talents with an emphasis on innovation spirit and practical ability (Feng, 2002); a scientific quality concept of kindergarten education should be able to promote the all-round, personalized and sustainable development of children while facilitate the self-development of each child (Liu, 2012). Besides, it has to take the questions such as "is the quality objective or subjective", "who decides the connotation of quality" and "how to evaluate the quality" into consideration when it aims to make a clear definition of kindergarten education quality ( $\mathrm{Su} \& \mathrm{Xu}, 2010)$. Because diverse demands require people to have multiplex visions and views to the concept of quality, most of the scholars agree that kindergarten education quality is developmental and a scientific quality concept should be dynamic, diverse and developmental.

\subsubsection{Research on Elements of Kindergarten Education Quality}

Most of Chinese scholars believe that kindergarten education quality includes condition quality or structure quality, process quality, outcome quality (Feng, 2011; Yu, 2013; Liu, 2012; Guo, 2013). Condition quality or structure quality includes the scale of classes, the proportion of teachers and children, teachers' qualification, the number and quality of books, toys and teaching tools, and the per capita space and etc. Process quality includes how the education work in kindergarten is carried out, what learning experience it provides to children and how to provide. Outcome quality refers to all physical and mental development aspects of children.

In conclusion, the current researches in China mainly analyze the elements of kindergarten education quality from three dimensions: condition (structure), process and outcome. Condition quality and process quality decide the outcome quality, and the process quality is the most important one (Zhou, 2012; Feng, 2011).

\subsubsection{Research on Present Situation of the Quality of Kindergarten Education}

Chinese scholars have made different scales of survey researches on present situation of the kindergarten education quality in recent years (Liu, 2011; Liu et al., 2008; Tian et al., 2013). Through the researches on kindergarten education quality in 11 provinces of China, Liu Zhanlan et al. (2011) have found: firstly, the characteristics showed by the current kindergarten education include good physical environment, teachers being younger and professional, half-day activities with comprehensive content and the operating practice serving as children's main learning approach; secondly, the prominent problems existing in the current kindergarten education include inappropriate learning materials, arbitrariness of course arrangement, imbalance of learning content, less attention and listening from teachers to children, and less language expression and communication of children; thirdly, kindergartens in districts and counties have less quality management and assessment processes, are lacking of proper quality assessment tools and the professional guidance to them need to be strengthened. Through surveys on class environment quality of 26 kindergartens with different systems in Shanxi province, Liu Yan et al. (2008) have found: in general, the education environment quality of kindergartens set up by the education department is better than that of others; the overall quality of private kindergartens is not high and has huge differences between each other. Besides, the surveys also find that kindergartens with different systems are all likely to provide high quality class education environment. 


\subsubsection{Research on Evaluation Standard}

"Evaluation standard" means what we need to evaluate. Scholars have different understandings on this. Liu Yan (1998) believes that the quality evaluation on kindergarten education includes four standards: the quality standard of employees (including qualifications and professional experience of employees, etc.), the responsibility standard of staff (including how teachers should perform various links in daily work, etc.), the efficiency standard (including the usage rate and the rational utilization degree of grounds, equipment and machines, etc.), the effect standard (including the development state of children, services for parents, adaption situation of children after enrolment, etc.). Guo Lingjing et al. (2013) point out that the goal of kindergarten education is to promote children's development and the key factors that affect the development of children in kindergarten should be served as important indicators in the quality evaluation system. The main factors are: process quality, structure quality and orientation quality. Orientation quality refers to education views, values and beliefs of adults who participate in the education process.

Up to now, China has no nationwide evaluation standard on kindergarten education quality. Provinces and cities have begun to establish kindergarten acceptance (or evaluation) standard since 1980s and 1990s, and these standards also serve as general reference for the practice of Chinese kindergarten education. Through studying quality evaluation standards of partial provinces, researchers have found that the standards mainly include five elements which are staff condition, material condition, education activity, children's development and kindergarten management. Proportions of elements in different areas are different (Liu \& Dai, 2010). However, there are some common problems in the existing quality evaluation standards such as paying more attention on result than on process, more on similarity than on difference, more on preset than on generation (Qian, 2012).

\subsubsection{Research on Evaluation Tools}

Nowadays, the international evaluation on preschool education quality usually adopts observation measurements such as ECERS-R, ECERS-E, CIS and CLASS. Chinese scholars mainly focus on the following aspects in the researches on evaluation tools: firstly, they make reviews and introductions to the above rating scales (Liu et al., 1998; Liu, 2004); secondly, they conduct researches on Chinese kindergarten education quality by using above rating scales (Hu \& Zhu, 2009); thirdly, they revise the above revaluation tools and apply the revised tools into the local researches (Liu, 2008). In addition, the research team led by Liu Zhanlan has developed ten evaluation tools for quality evaluation of kindergarten education, including status investigation of preschool class, teachers' observation on children's half-day activities, observation on children's activity, observation on teachers' behavior, mutual observation between teachers and children, and children's development evaluation (Liu et al., 2009).

Since the current quality evaluation standards of Chinese kindergartens mainly adopt the provincial evaluation and acceptance standards and have no nationwide evaluation standards, it is necessary to develop a set of self-evaluation scale for preschool education institutions based on the national preschool quality standards.

\subsubsection{Research on Present Situation of Evaluations}

The literature study has found that quality evaluation on Chinese kindergarten education mainly has following problems. Firstly, the evaluation content and standard themselves exist problems such as paying more attention on condition and result while ignoring the quality evaluation on process; the evaluation contents more emphasize on static contents and ignore dynamic contents; evaluation indicators are ambiguous and their operability is not clear. Secondly, the evaluation subject is unitary and simple for the evaluation is mainly made by the local government administrative departments and subordinate institutions while the evaluation personnel are mainly composed of governmental staff. Thirdly, the evaluation mainly focuses on quantitative evaluation and ignores the qualitative evaluation (Liu, 2006).

In order to resolve existing problems in the quality evaluation system of Chinese kindergarten education, most of the scholars advocate that the evaluation contents should emphasize on process and quality, and the evaluation indicators should be clearer and operational (Wu, 2012; Liu, 2006); some scholars also claim that it is necessary to develop a nationwide preschool education quality evaluation standard which is suitable for the current situation of China so as to ensure the quality bottom-line of preschool education organizations and narrow regional education differences (Qian, 2012). What's more, the evaluation subject should be diversified, education intermediary organizations should be cultivated and a third party evaluation mechanism shall be introduced (Cai, 2009). Finally, the evaluation should be associated with improvement thus to form a quality assurance system.

\subsubsection{Research on Quality Assurance of Kindergarten Education}

The discussion and study about topics of the importance of education quality, the quality assurance and education quality improvement are in different literatures. In order to guarantee the preschool education quality, 
the scholars believe that the government needs to focus on three links, namely, the link of kindergarten establishment, the link of quality supervision and the link of teachers. The specifics are the establishment of kindergarten access system, the improvement of quality evaluation and supervision system on preschool education, and to incorporate private kindergartens into education supervision systems (Liu, 2010). It mainly can be strengthened from the following aspects: first, it should require the establishment of quality evaluation and supervision system (Feng, 2011; Zhou, 2012); second, it needs to develop a nationwide quality standard (Zhou, 2012; Qian, 2012); third, it has to improve the kindergarten establishment and cancellation mechanism (Zheng, 2013); fourth, it should establish and perfect the education personnel system (Pang, 2012; Cai, 2009); fifth, it has to improve the funding and management system (Cai, 2006; Li, 2012).

\section{Discussion}

After studying the literatures on kindergarten education, the researcher will review the existing literatures from research paradigm and research content:

\subsection{Research Paradigm}

In terms of research paradigm, the evaluation on present situation of kindergarten education quality mainly adopts the empirical research paradigm, taking different ranges of samples around the country. The research on quality assurance of kindergarten education mainly uses the literature analysis method and experience summary method, making descriptive analysis and discussion. Since the research on kindergarten quality will inevitably involve quality evaluation and supervision, it determines the research to use empirical research paradigm. However, in order to establish a nationwide quality assurance system, it has to pay attention to both similarities and differences due to the huge economic and educational differences in the urban and rural as well as in regional areas in China. It requires that this kind of research should not only purse quantitative research paradigm, but also needs to combine with qualitative field investigation and to deeply understand the social ecosystem of the development of private kindergarten and care about demands of stakeholders thus to make comprehensive and systematic analysis on the quality assurance of private kindergarten education.

\subsection{Research Content}

As for the research contents, Chinese scholars mainly discussed the concept of quality, elements and evaluation of kindergarten education. The research on the current situation of kindergarten education quality in different regions of China, especially, provides empirical basis for the research of quality assurance. Meanwhile, the Chinese scholars discuss the quality assurance issues from different elements of the kindergarten education quality. The researches concern about the analyses of issues such as quality standard, supervision and certification, which are stated in foreign scattered literature reviews on kindergarten education quality assurance system. Some researchers have shown that the supervision dominated by government is an important measure to safeguard the quality of kindergarten education (OECD, 2006). However, China has not established a systematic quality assurance system for kindergarten education.

\section{Enlightenment}

The researches on Chinese preschool education are largely affected by macro policies. In 2010, China officially launched the National Medium and Long Term Education Reform and Development Plan Outline (2010-2020) and preschool education is firstly listed in the Outline as a separate chapter, which reflects the state's unprecedented attention to preschool education; soon afterwards, Chinese State Council issued the Some Opinions of the State Council on Developing Current Preschool Education and decided to implement the Three-Year Action Plan for Preschool Education. All of these measures provide important conditions and opportunities for the development of preschool education, and also create good external supporting environment for researches on preschool education. This is the answer why the research on kindergarten education quality has a sudden and rapid growth in 2010 .

But, researches will not develop behind closed doors. The academic research at least has two basic functions: first, it can promote the reform of education practice and improve education quality; second, it can make positive impact on formulation of education policies. However, the basic functions of the academic research on preschool education fail to play an effective role in China: preschool education practice is alienated from researches and mainly guided by the market and parents. Most of researches on kindergarten education are interpretations of policies while policies guide the research direction and keynote. Therefore, under the circumstance of increasing funds investment on preschool education and intensive issues of policy document, it urgently needs the academic research on preschool education to give full play of its functions to enhance interactive effects between academic research and practice reform as well as the interactive effects between academic research and policy formulation. 


\section{Acknowledgments}

This paper is a research result of "A strategy study of pre-school education development in western China in the context of the new-type of urbanization" the key project of 12th Five-Year Plan in National Education Science under the Ministry of Education of the PRC (Project No: DGA130254).

\section{References}

Cai, Y. Q. (2006). On reconstitution of financial investment system related to Chinese early childhood education. Educational Research and Experiment, (2), 21-24.

Cai, Y. Q. (2009). Problems exist in Chinese preschool education. Educational Research and Experiment, (1), $13-15$.

Feng, X. X. (2002). Early childhood education should be based on the lifelong sustainable development of children. People's Education, (6), 25-26.

Feng, X. X. (2011). Opportunity and quality are equally important for preschool education development. China Education Daily (2nd ed.).

Guo, L. J. (2013). Solve preschool education quality guarantee and promotion problems with "systematic" thoughts. Studies in Early Childhood Education, (9), 8-13.

Heckman, J. J., \& Masterov, D. V. (2007). The productivity argument for investing in young children. Massachusetts: National Bureau of Economic Research Cambridge. http://dx.doi.org/10.3386/w13016

Heckman, J. J., Moon, S. H., Pinto, R., Savelyev, P. A., \& Yavitz, A. (2009). The rate of return to the high scope perry preschool program. Journal of Public Economics, 94(1-2), 114-128. http://dx.doi.org/10.1016/ j.jpubeco.2009.11.001

Hu, B. Y., \& Zhu, Z. S. (2009). The United States "children learning environment rating scale" and its preliminary application in China. Early Childhood Education, (11), 47-51.

Li, H. (2012). Dilemma of reform on financial investment system related to Chinese preschool education. Journal of China Women's University, (4), 114-120.

Liu, L. X. (2006). Misunderstandings in and adjustment strategies for evaluation operations of kindergarten education quality in China. Studies in Early Childhood Education, (8), 85-87.

Liu, X. (2001). Education quality of kindergarten units-Concepts and constitutions. The Modern Educational Journal, (4), 11-15.

Liu, X. (2012). On kindergarten education quality. Early Childhood Education (Educational Science), (10), 5-8.

Liu, X., \& Dai, S. X. (2010). Research on education quality standard of Chinese kindergartens. Comment on Chinese Education Policy, 144-157.

Liu, Y. (1998). On several problems of education quality evaluation in kindergarten units. Studies in Early Childhood Education, (3), 14-17.

Liu, Y., Li, Z. Y., Pan, Y. J., \& Zhang, T. (2008). Comparison of education environment quality between kindergartens with different systems. Studies in Early Childhood Education, (8), 7-11.

Liu, Z. L. (2009). Quality evaluation manual of Chinese kindergarten education. Beijing: Educational Science Publishing House.

Liu, Z. L. (2010). The significant premise of kindergarten enrollment rate is preschool education quality [J]. Studies in Early Childhood Education, (5), 9-10.

Liu, Z. L. (2011). Evaluation on education quality of Chinese kindergartens-Researches on kindergarten education quality in 11 provinces and cities. Beijing: Educational Science Publishing House, 9, 386-390.

Nores, M., \& Barnett, W. S. (2010). Benefits of early childhood interventions across the world: (Under) Investing in the very young. Economics of Education Review, 29, 271-282. http://dx.doi.org/10.1016/j. econedurev.2009.09.001

OECD. (2006). Starting strong II: Early childhood education and care. OECD, Paris.

OECD. (2012). Starting strong III: A quality toolbox for early childhood education and care. OECD, Paris.

Pang, L. J., \& Hong, X. M. (2012). Report on development of Chinese preschool education. Beijing: Beijing Normal University Press, 181-182.

Qian, Y. (2012). Development and enlightenment of evaluation researches on Australian preschool education quality. Studies in Foreign Education, (9), 3-7. 
Qian, Y. (2012). Development characteristics and trend analysis of quality monitoring system on global preschool education and relevant enlightenment on Chinese education. Studies in Early Childhood Education, (12), 14-18.

Reynolds, A. J., Temple, J. A., Robertson, D. L., \& Mann, E. A. (2002). Age 21 cost-benefit analysis of the title I Chicago child-parent centres. Educational Evaluation and policy Analysis, 24(4), 267-303. http://dx.doi.org/ 10.3102/01623737024004267

Schweinhart, L. J., Barnes, H. V., \& Weikart, D. P. (1993). Significant benefits: The high/scope perry preschool study through age 27. Monographs of the High/Scope Educational Research Foundation, 10, High/Scope Press, Ypsilanti.

Schweinhart, L. J., Montie, J., Xiang, Z., Barnett, W. S., Belfield, C. R., \& Nores, M. (2005). Lifetime effects: The high/scope perry pre-school study through age 40. High/Scope Educational Research Foundation, Ypsilanti, MI.

Sheridan, S. (2007). Dimensions of pedagogical quality in preschool. The International Journal of Early Years Education, 15, 198-217. http://dx.doi.org/10.1080/09669760701289151

$\mathrm{Su}$, G. M., \& Xu, Y. (2010). Evaluate early education quality with three dimensions. Studies in Early Childhood Education, (9), 22-25.

Sylva et al. (2006). Capturing quality in early childhood through environmental rating scales. Early Child Research Quarterly, 21, 76-92. http://dx.doi.org/10.1016/j.ecresq.2006.01.003

Sylva, K., Melhuish, E., Sammons, P., Siraj-Blatchford, I., \& Taggart, B. (2004). The effective provision of pre-school education (EPPE) project: Findings from preschool to end of key stage 1. London, England: University of London. Retrieved November, 2008, from http://www.ioe.ac.uk/projects

Tian, B. Q., Wang, S. A., \& Yang, X. P. (2013). Kindergarten education environment quality research-based on a survey of 36 kindergartens in Sichuan Province. Early Childhood Education (Educational Science), (3), $18-23$.

UNESCO. (2007). Strong foundations: Early childhood education and care. EFA Global Monitoring Report. UNESCO, Paris.

Wu, G. (2012). Reflection of evaluation on Chinese kindergarten education quality: Problems and viewpoints. Early Education (Educational Science Research), (2), 22-25.

Xue, J. N. (2012). Research on evaluation indicator system of kindergarten education quality (master's thesis). Shanghai Normal University.

Yu, Y. P. (2013). How to observe, evaluate and implement-Think twice and practice critically in issues of preschool education quality. China Education Daily (1st ed.).

Zheng, Z. Y. (2013). Study on government regulations to private kindergartens (Doctoral dissertation). Southwest University, China.

Zhou, X. (2003). Education quality connotation of kindergarten units and influences on child development. Studies in Early Childhood Education, (7/8), 34-38.

Zhou, X. (2012). Meaning and views of establishing a nationwide preschool education quality monitoring system. Studies in Early Childhood Education, (1), 23-26.

\section{Notes}

Note 1. CNKI (China National Knowledge Infrastructure) is the largest literature retrieval platform in China.

Note 2. The literature samples of the research refers to research results got in the mainland of China, not including that of Hong Kong, Macau and Taiwan.

\section{Copyrights}

Copyright for this article is retained by the author(s), with first publication rights granted to the journal.

This is an open-access article distributed under the terms and conditions of the Creative Commons Attribution license (http://creativecommons.org/licenses/by/3.0/). 